لوبعية العربية للحفاظ على الفطريات

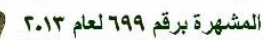
Decreed by No. 699/2013 b Society for Fungal Conservatio
Contents lists available at Egyptian Knowledge Bank

Microbial Biosystems

Journal homepage: http://mb.journals.ekb.eg/
INTERNATIONAL SCIENTIFIC JOURNAL

OF MicRoBiAL BIOLOGY

\title{
Survey on Sarcocystis infection in imported male cattle carcasses slaughtered at Duhok abattoir, Kurdistan region of Iraq
}

\author{
Teroj A. Mohamed ${ }^{1 *}$, Shivan N. Hussein ${ }^{2}$, Mohammed S. Shukur ${ }^{2}$, Rojeen A. \\ Mohammad $^{3}$, Agah A. Ali ${ }^{3}$, Lolav N. Khalil ${ }^{3}$ \\ ${ }^{1}$ Pathology and Microbiology Department, College of Veterinary Medicine, University of Duhok, Iraq. \\ ${ }^{2}$ Medicine and Surgery Department, College of Veterinary Medicine, University of Duhok, Iraq. \\ ${ }^{3}$ College of Veterinary Medicine, University of Duhok, Iraq.
}

\section{Article history \\ Abo Nahas HH \\ Keywords \\ Sarcocystis \\ Imported cattle \\ Conventional \\ Bradyzoite \\ Histology}

ARTICLE INFO

Received 15 August 2020

Received revised 10 September 2020

Accepted 15 October 2020

Available online 20 October 2020

(C) Mohamed et al., 2020

Corresponding Editor:

Abdel-Azeem AM

\begin{abstract}
Sarcocystis is considered as a common zoonotic coccidian parasite that infects intermediate hosts orally through ingestion of contaminated graze or water with protozoa oocyte. The purpose of study is to demonstrate the incidence of Sarcocystis infection in imported cattle in Duhok abattoir and achieve the gold conventional method for muscular tissue cyst and bradyzoites detection. Muscular tissue samples have been collected from esophagus, heart and diaphragm of 150 cattle. From a total of 1350 inspected samples (diaphragm, esophagus and heart) from three different imported origin have been $94 \%, 92 \%$ and $41.3 \%$ samples infected respectively as well as significant differences $(p<0.01)$ in the distribution of Sarcocystis infection among organs included and microscopic method used while no significant been found in terms of the animal origin source. Moreover, acid pepsin digestion method has shown high sensitivity in detection of Sarcocystis infection. The infection with Sarcocystis is common in imported cattle and epidemiological studies must be conducted to evaluate the country endemic with the infection.
\end{abstract}

Published by Arab Society for Fungal Conservation

\section{Introduction}

Sarcocystosis, as an intracellular protozoan parasitic disease, can be considered one of the zoonotic diseases that is caused by a species of parasites belonging to the phylum Apicomplexa and family Sarcocystidae (Dubey et al. 2015).

The infection by Sarcocystis characterized by cyst formation in the muscle of the intermediate host which causes muscular Sarcocystosis or intestinal Sarcocystosis when it invades the lamina propria of the final host due to the presence of marco and micro-gamonts and oocyst (Dubey et al. 2015). This coccidian parasite is considered obligatory in the relationship with carnivorous as the definitive host and non-pathogenic relationship with herbivorous or omnivorous as intermediate hosts viz. human, sheep, goat, cattle, pig, and horse (Dubey et al. 1989). However, the main source of the infection in human from meat and meat production through the ingestion of encysting parasites in the tissue of the herbivorous or omnivorous hosts which contain bradyzoite

\footnotetext{
* Corresponding author

E-mail address: teroj.mohamed@uod.ac (Teroj Abdulrahman Mohamed)
} 
in addition to the infection occurred by ingestion or drinking water has been contaminated by oocysts excreted from the final host (Tian et al. 2012). The infection is mostly characterized by asymptomatic and in some rare cases may lead to gastrointestinal disorder and this nearly correlated with infection by $S$. hominis. The number of the zoonotic disease transmitted from animals to humans is more than 200 diseases and they include Cysticercosis, Echinococcosis, Ascariasis, Trichinosis, and Sarcocystosis (Frenkel and Smith 2003).

Sarcocystosis infection in livestock animal characterized by non-obvious or clear sign but may have economic impacts associated with Sarcocystis species infection, the highly severe infection may lead to abortion, decrease in milk yield, loss of wight gain, anemia, fever and muscle weakness and lead to neurological sign in some cases and death of the intermediate host such as cattle, sheep and goat (Chhabra and Samantaray 2013). Moreover, the certain species affecting cattle are Sarcocystis cruzi, S. hominis, S. hirsuta, S. heydorni and $S$. rommeli (Dubey et al.1989) and the prevalence rate in cattle is nearly $100 \%$ in most regions of the world (Hussein et al. 2017). Furthermore, Fayer et al. (2015) has explained that $S$. hydronium is mostly related to cattle-human lifecycle infection.

Estimation of the coccidian protozoa prevalence (cyst either bradyzoite) form by using various approach including Macroscopy (detection of Macro-cyst) Microscopy (Pepsin /Trypsin digestion, impression on slide or squash squeezing smear and histopathology approach), Serology either by ELISA or IFA and also molecular approach is recently wildly used for detection of the gene prevalent (Bahari et al. 2014; Metwally et al. 2014; Meistro et al. 2015; Banothu et al. 2017; Zangana and Hussein 2017).

This study aimed to detect the prevalence of Sarcocystis infection in the imported cattle in Duhok province by using conventional methods and comparing between different identification techniques to achieve a gold method for tissue cyst zoite and bradyzoite detection. Also, to shed the light on how the diseases transferred and may be affected human health in Duhok.

\section{Materials \& Methods}

\section{Samples collection}

This study is carried out between September 2019 to August 2020 with a total number of 150 (50 cattle/country of origin) samples randomly collected from male cattle imported from Brazil, India, and Malaysia respectively from Duhok abattoir. A total number of 450 samples representing organs under investigation (esophagus, heart and diaphragm) were collected from 150 male cattle imported from the three countries. All male cattle were selected to detect the presence and/or absence of the cyst or bradyzoites in muscular tissues. Approximately $100 \mathrm{~g}$ from each beef muscular tissue samples have been weighed and transferred in closed plastic bags in an icebox within the 3 hours to the parasitology Laboratory at the College of Veterinary medicine, University of Duhok for further examination and all samples have been stored in a refrigerator without preservatives.

\section{Macroscopic examination}

Postmortem examination is performed at the abattoir to explore the presence of macrocyst by naked eye. A sterile blade is used to cut each muscular tissue to a small piece (3-5 $\mathrm{mm}$ ) and assessed by using a hand lens in order to visualize Sarcocystis macrocyst presence as white rice grain according to El-Kady et al. (2018) and Mavi et al. (2020).

\section{Microscopic examination}

A total number of 1350 samples have been collected, treated and examined by three techniques namely: squeezing, squash for detection of cyst and digestion methods for detection of bradyzoites, and each positive sample was confirmed histopathologically.

\section{Muscular tissue squeezing (tissue grinds) method}

A modified method which is mainly based on two previously described techniques by Latif et al. (1999) and Bittencourt et al. (2016) was adopted. From each muscular tissue nearly 20-25 g homogenized by grinding manually in the garlic /crush metal instrument and mixed with 1-1.5 $\mathrm{ml}$ of Phosphate-buffered saline (PBS) $\mathrm{pH} 7.2$ then sifted and pass in three layers gauze and centrifuged at $600 \times \mathrm{g}$ for $10 \mathrm{~min}$. The supernatant was discarded followed by smearing of sediment layer, dried on a slide and fixed in absolute methanol. Smears were stained by Giemsa and examined under microscope.

\section{Muscle squash method}

For muscle squash examination, $1 \mathrm{~g}$ of muscular tissue cut it into small pieces (3-5 mm thick) and forced between two glass slides and examined microscopically at 40x according to Latif et al. (1999) and Saied et al. (2009).

\section{Pepsin hydrochloric acid digestion method}

For identification of the bradyzoites from each muscular tissue collected, $50 \mathrm{~g}$ is used and homogenized away from normal saline then enforced by adding normal saline and homogenized more than 3 minutes subsequently incubated with $100 \mathrm{ml}$ of digestion solution $(1.3 \mathrm{~g}$ pepsin, $3.5 \mathrm{ml}$ of $1 \% \mathrm{HCL}$ and $25 \mathrm{~g} \mathrm{NaCl}$ in $500 \mathrm{ml}$ of distilled water) for 30 mins to one hour at $37^{\circ} \mathrm{C}$. 
The digested muscular tissue is sieved through two layers of gauze and centrifuged at $800 \times \mathrm{g}$ for $10 \mathrm{~min}$, discard supernatant, the process repeated twice, and 0.5-10 $\mathrm{ml}$ of PBS (PH 7.2) added to resuspend the sediment. The bradyzoites has been detected by smearing drops of resuspended sediment on a dry clean slide, stained with Giemsa after fixing the smear in methanol (Barham et al. 2005; Dubey et al. 2015).

\section{Histopathological examination}

Positive Sarcocystis 'infected samples were cut into 1x1cm $\left(1 \mathrm{~cm}^{2}\right)$ slices and fixed in $10 \%$ formalin and handled for histopathology examination in Vin histopathology laboratory in Duhok private hospital. Dehydration in ascending series of ethanol followed by embedding in paraffin and $5 \mathrm{~mm}$ section have been prepared and stained with Hematoxylin and Eosin (H\&E) followed by examination microscopically under 10, 20, 60 and 100 magnification (El-Kady et al. 2018; Khoshsima et al. 2018).

\section{Statistical Analysis}

All data obtained were analyzed statistically, means differences are estimated with Chi-Square test using SPSS at level (P>0.01) according to Taib et al. (2016).

\section{Results}

The incidence of Sarcocystis was examined by using both macroscopic and microscopic methods of detection. The overall incidence of Sarcocystis' frequency of infection out of 450 samples collected from 150 imported male cattle carcasses is $76 \%$ even cyst or bradyzoite microscopically recorded. Results showed that significant differences correlated at $p<0.01$ between visual inspection and light microscopic methods (Figure1).

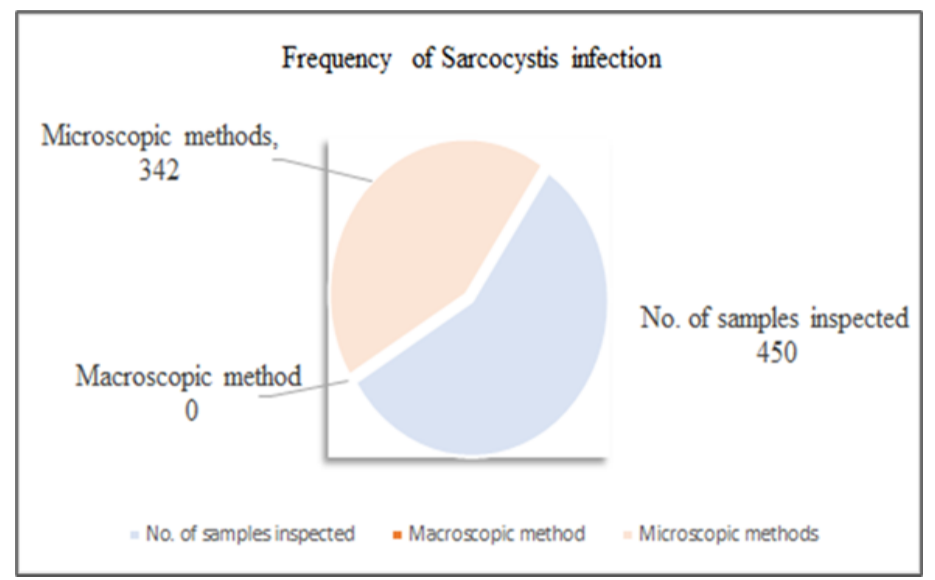

Fig 1. Frequency of Sarcocystis infection during this study.

\section{Sarcocystis developmental phases}

As shown in figure (2) various developmental phases of Sarcocystis infection have been recorded microscopically. In table (1) the stronger detection evidence has recorded by pepsin hydrochloric acid digestion, muscle squeezing techniques and muscle squash method by recorded 383 $(85 \%), 373(83 \%), 270(60 \%)$ respectively. Data analysis showed significant differences in terms of amide microscopic method used at $p<0.01$.
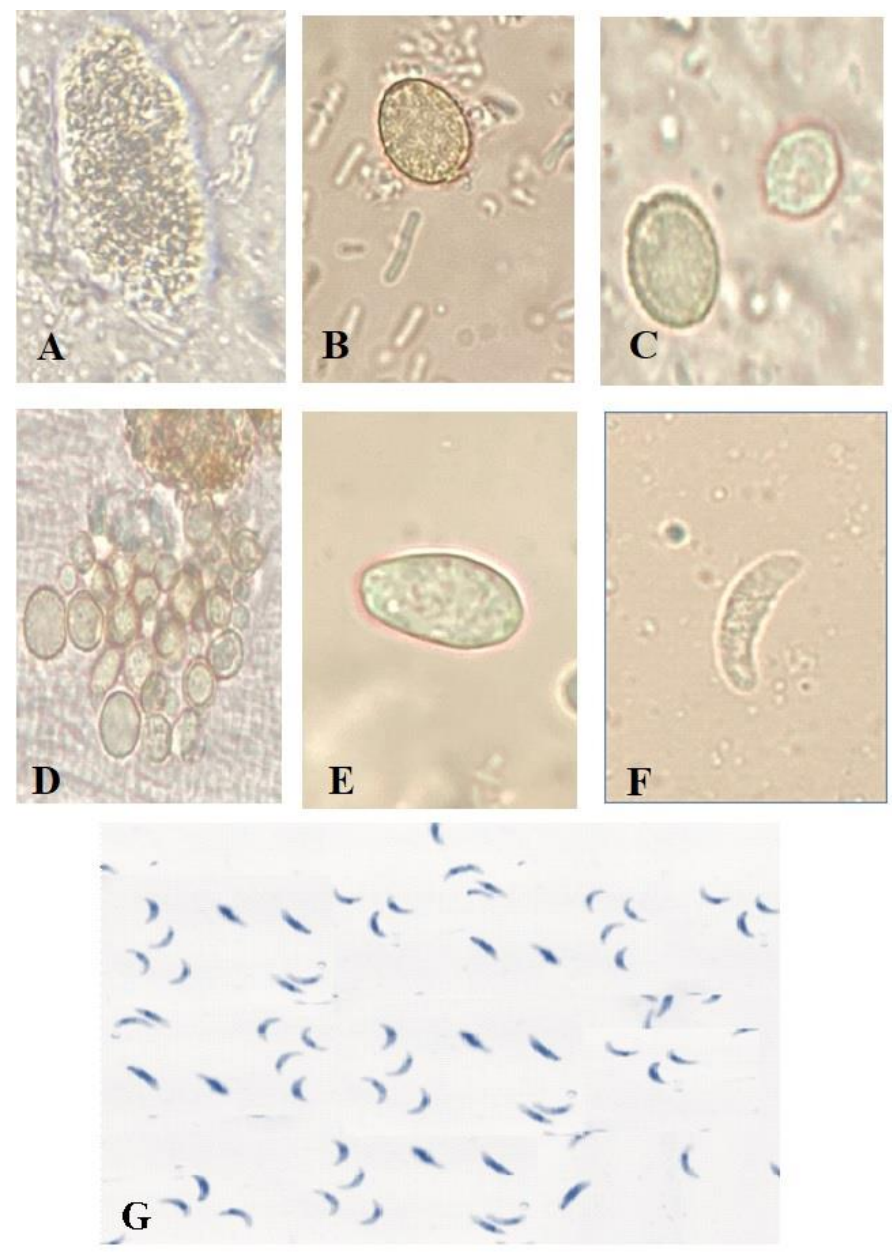

Fig 2. (A-F) Different developmental stages of Cystozoite in muscular tissue, (G) Bradyzoite from pepsin digestion method stained by Giemsa.

\section{Sarcocystis distribution in different organs}

Concerning the organ susceptibility to Sarcocystis infection, the results showed that the utmost infection established in diaphragm (94\%), esophagus (92\%) and heart (41.3\%) as recorded in table (2) and there are significant differences among organs to infect at $p<0.01$. 
Table 1 Sensitivity of microscopic methods in cyst zoite and bradyzoite detection

\begin{tabular}{cccc}
\hline No. Samples & squeezing muscular tissue & Squash muscular tissue & Pepsin hydrochloric acid digestion \\
\hline 450 & $373(83 \%)$ & $270(60 \%)$ & $383(85 \%)$ \\
\hline
\end{tabular}

Table 2 Sarcocystis infection distribution among organs

\begin{tabular}{lccc}
\hline \multicolumn{1}{c}{ Organ inspected } & No. of organs inspected & Infected organ & \% \\
\hline Diaphragm & 150 & 141 & 94 \\
Oesophagus & 150 & 138 & 92 \\
Heart & 150 & 62 & 41.3 \\
\hline
\end{tabular}

\section{Distribution of Sarcocystis infection among different importing countries of male cattle}

Out of 150 male cattle imported under investigation, Brazil came first by recording $78 \%$ of incidence of infection followed by India and Malaysia (75\%). No significant differences were recorded (Fig. 3) between animal imported origin at $p>0.01$.

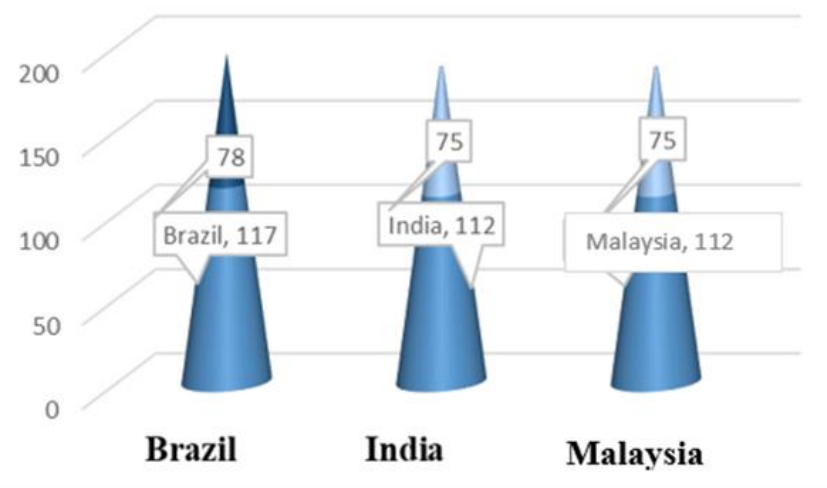

Fig 3. Distribution of Sarcocystis infection among different importing countries of male cattle.

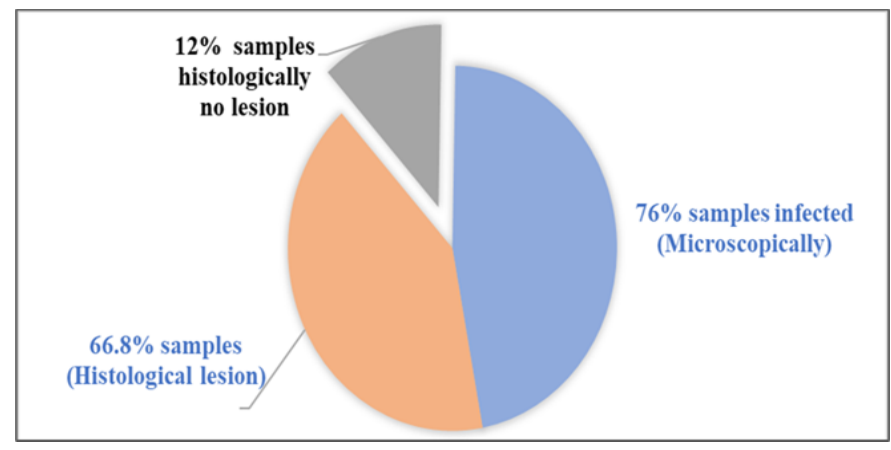

Fig 4. Variance between acid digestion results and histological lesions.

\section{Histopathology}

Examination of cross sections of the muscular tissue of 342 samples have been listed with the presence of cyst or bradyzoites by light microscopy revealed that Sarcocystis histological lesion in 301 (88\%) samples (Fig. 4). None of the Sarcocystis were directly connected with an inflammatory response as shown in figure (5).
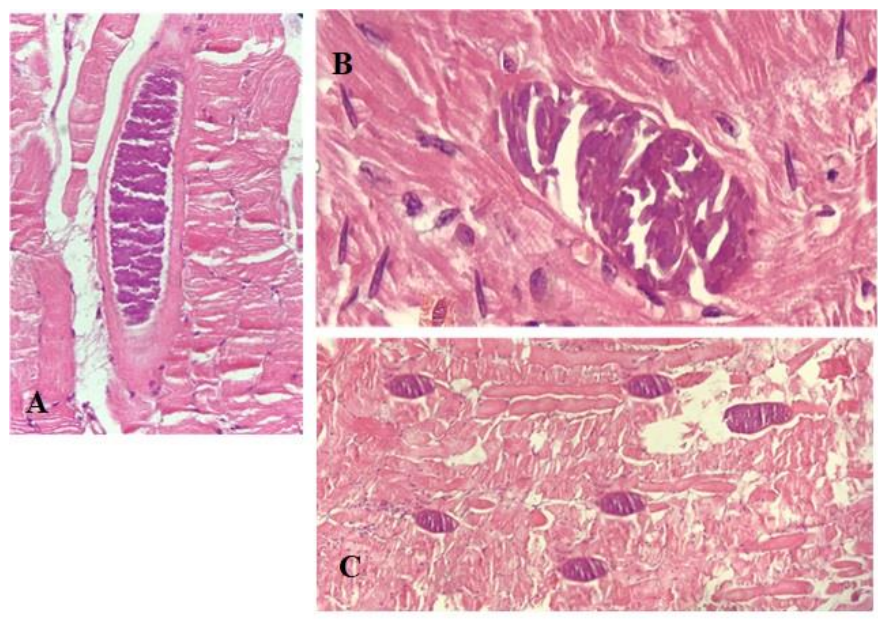

Fig 5. Sarcocystis infection in the cattle stained by H\&E (x400), A- longitudinal section of diaphragm with presence of spindle shape of cyst, B-Myocardium, spindle shape microcysts, and C- Macrocysts in esophageal tissue.

\section{Discussion}

One of the main routes of infection is when the cattle feed on contaminated pasture or water with the oocyst/sporocyst of the parasite. The prevalence of infection has been $76 \%$ among 150 imported cattle while it was $96 \%$ according to Al-Nakshabandi (2008) and he explained that the prevalence rate depends on the method used for diagnosis while the incidence of infection was $82.9 \%$ serologically (Haddadzadeh et al. 2004). 
According to a study carried by Muhamed and $\mathrm{Al}^{-}$ barwary (2016), they have been found that about $4.8 \%$ of the shepherd dogs have infected with the Sarcocystis spp and that's why highly livestock infection recorded by Latif et al. (1999). This is may be referred to short pre-patent period and shedding (nearly 100-200 million of oocysts or sporocyst) by the carnivorous host with ability of this infective form to survive in different environmental conditions for many months in addition to the short period of second cyst merozoites generation formation in the muscle tissue about 40 days post inoculation (Wee and Shin 2001). Our work showed that all imported male cattle not less than 18 months when slaughtered at Duhok abattoir and this increase animal probability to receive the infection from the contaminated pasture with sporulated sporocyst or oocyst because most of the calves weaned at 6-8 months of age.

In addition to 450 organs inspected during this study and macroscopic cysts haven't seen while Ahmed et al. (2016) initiated the presence of macrocyst in $7.5 \%$ of the cattle, however, hasn't been recorded as mentioned by Shekarforoush et al. (2005).

According to Al-Nakshabandi (2008) the diagnostic method would affect the presence and/or absence of tissue cyst and bradyzoites in the muscles. Our study findings show a significant difference between the different methods applied for identification of Sarcocystis spp. Hydrochloric acid digestion method used as a great measurement for any organ associated with presence of the microcyst development stage and it gives high accuracy rate up to $100 \%$ with presence of the bradyzoites featured in banana shape and the nucleus appeared towards to the posterior end when stained by $\mathrm{H} \& \mathrm{E}$ and toluidine blue and considered as a gold standard method by many researchers (Arshad et al. 2007; Zangana and Hussein 2017).

Significant differences have been observed at $(p<0.01)$ concerning to the organ infected and high rate of infection has demonstrated in diaphragm and esophagus $(94 \%$ and $92 \%$ ) respectively and followed by myocardium muscle tissue infection $(41.3 \%)$. The results in accordance with previous reports by Ahmed et al. (2016) and Januskevicius et al. (2019) and the consequence of diaphragm high rate infection discussed by Januskevicius et al. (2018) as correlation of increasing the fat content in the infected animal body as a result of proinflammatory response due to infection with coccidian parasites and intensive presence of the mitochondria in the muscle fibres. However, Faghiri et al. (2019) recorded in their study that the most infected tissue was cardiac muscle $58.8 \%$.

Sarcocystis is a common and most worldwide distributed disease and its importance for animals are corresponding to its importance to human health due to the most common cattle-human infecting cycle. In addition, these intermediate host are acting as a final host for some specific Sarcocystis species (Dubey et al. 2015) and the infection in cattle squealy lead to economic losses viz: decrease in meat quality, milk production and abortion (Dubey and Bergeron 1982; Ahmed et al. 2016). Our data proved that $78 \%$ of imported cattle from Brazil, $75 \%$ from India and Malaysia were microscopically diagnosed infected with Sarcocystis (presence of cyst and bradyzoite). Other studies by other researchers showed low rate of infections e.g. Venu and Hafeez (2000), Gjerde (2016) and Ferreira et al. (2018) who recorded $42.6 \%, 54.78 \%$ and $40.8 \%$ rate of infection of Brazilian, Indian and Malaysian cattle respectively.

The high rate of infection and presence of different developmental cyst merozoite generation phase is regarded due to the contact and graze of the imported cattle for at least 2-3 months in contaminated pasture before slaughtering as a most common prevalent habit among livestock animals' owners in Kurdistan region however the pasture may contain sever amount of shaded oo-sporo/cyst (Fayer 1977; Khoshsima et al. 2018). Mousa et al. (2016) diagnosed $70 \%$ of the frozen meat came from Brazil and India infected with Sarcocystis by molecular techniques.

Evaluation of obtained results from hydrochloric acid digestion with histological results in agreement with Taib et al. (2016) and Fayer (2004). The incidence rate of Sarcocystis in enzymatic digestion method (95\%) is higher than histological analysis (80\%) without any inflammatory response due the merozoite encysted within the thin or thick cyst wall according to the Sarcocystis taxon and most of the granulomatous inflammation regarded to the myositis, including glossitis and inflammation of cardiac muscle appear when cyst are ruptured. The result supported our observation that histological section revealed only the presence of Sarcocystis developmental phase in a prepared section for that more section needed to support neither the slaughtered animal infected or not. However, Zangana and Hussein (2017) explained the histological lesion give high intensity of cyst presence in different size and shape in tissue sample.

\section{Conclusion}

Our findings show that the imported male cattle have a high incidence of microscopic developmental phase of tissue cyst and bradyzoite of Sarcocystis spp infection, which can be a risk to animals and human health. The livestock animals must be prevented from ingesting the sporocyst stage from carnivorous or human feces (when serving as the definitive host) by preventing of the animal food contamination. The meat should be thoroughly frozen when such preventive measure cannot be ensured and meat can harbor cysts. Cattle can be infected with more than one 
type of Sarcocystis at the same time, it can be presumed that the effect on the quality of meat and animal health status, so further studies should be considered because Sarcocystis pathogenicity is not accurately understood in many animal species till now.

\section{Conflict of interest}

The authors have no conflicts of interest to declare. All coauthors have seen and agree with the contents of the manuscript.

\section{Acknowledgments}

We would like to thank Dr. Pehal Mohammed Amedi, the Director of Duhok abattoir, for his unlimited support during collection of the study samples.

\section{Reference}

Al-Nakshabandi A (2008) Rative study on cattle Sarcocystosis diagnostic techniques in Duhok governorate. Bas J Vet Res 7(2):16-20.

Arshad M, Dalimi A, Ghaffarifar F (2007) Comparative study on Sarcocystis diagnosis in meat of slaughtered sheep in Tabriz. J Pajouhesh and Sazandegi 75: 6872.

Bahari P, Salehi M, Seyedabadi M, Mohammadi A (2014) Molecular identification of macroscopic and microscopic cysts of Sarcocystis in sheep in North Khorasan province, Iran. IJMCM 3(1):51.

Banothu D, Manchukonda U, Rayulu VC (2017) Diagnosis of bovine sarcocystosis by immunoflourescent antibody technique. J Parasitol dis 41(3):795-798.

Barham, M., Stützer, H., Karanis, P., Latif, B.M. and Neiss, W.F(2005) Seasonal variation in Sarcocystis species infections in goats in northern Iraq. Parasitology, 130(2):151-156.

Bittencourt MV, Meneses IDS, Ribeiro-Andrade M, de Jesus RF, de Araújo FR, Gondim LFP (2016) Sarcocystis spp. in sheep and goats: frequency of infection and species identification by morphological, ultrastructural, and molecular tests in Bahia, Brazil. Parasitol Res 115(4):1683-1689.

Chhabra MB, Samantaray S (2013) Sarcocystis and sarcocystosis in India: status and emerging perspectives. J Parasit Dis 37(1):1-10.

Dubey JP, Bergeron JA (1982) Sarcocystis as a Cause of Placentitis and Abortion in Cattle. Vet Pathol 19(3):315-318.

Dubey JP, Speer CA, Charleston WAG (1989) Ultrastructural differentiation between sarcocysts of Sarcocystis hirsuta and Sarcocystis hominis. Vet Parasitol 34(1-2):153-157.
Dubey JP (2015) Foodborne and waterborne zoonotic sarcocystosis. Food Waterborne Parasitol 1(1):2-11.

El-Kady AM, Hussein NM, Hassan AA (2018) First molecular characterization of Sarcocystis spp. in cattle in Qena Governorate, Upper Egypt. J Parasit Dis 42(1):114-121.

Faghiri E, Davari A, Nabavi R (2019) Histopathological Survey on Sarcocystis Species Infection in Slaughtered Cattle of Zabol-Iran/Zabol-Iran'da Kesilen Sigirlarda Sarcocystis Turlerinin Yol Actigi Enfeksiyonlar Uzerine Histopatolojik Inceleme. Turkiye Parazitol Derg 43(4):182-187.

Fayer R (1977) Production of Sarcocystis cruzi sporocysts by dogs fed experimentally infected and naturally infected beef. J Parasitol :1072-1075.

Fayer R (2004) Sarcocystis spp. in human infections. Clin Microbiol Rev 17(4):894-902.

Ferreira MS, Vogel, FSF, Sangioni LA, Cezar AS, Braunig, P, de Avilla Botton S, Camillo G, Portella LP (2018) Sarcocystis species identification in cattle hearts destined to human consumption in southern Brazil. Vet Parasitol 14:94-98.

Frenkel JK, Smith DD (2003) Determination of the genera of cyst-forming coccidia. Parasitol Res 91(5):384389.

Gjerde, B (2016) Molecular characterisation of Sarcocystis bovifelis, Sarcocystis bovini n. sp., Sarcocystis hirsuta and Sarcocystis cruzi from cattle (Bos taurus) and Sarcocystis sinensis from water buffaloes (Bubalus bubalis). Parasitol Res 15(4):1473-1492.

Hadadzadeh H, Raazi JM, Khazraeinia, P., TAHERI, M. and Rasekh, A (2004) Serological study on sarcosystosis in slaughtered buffaloes (Bubalus bubalis) using IFAT compare with meat inspection finding in ahvaz abattoir.

Hussein DE, Abu-Akkada SS, Bessat MS, Aggour MG, Otify YZ (2017) Molecular identification of Sarcocystis species in imported frozen beef in Egypt. Alex J Vet Sci 53(2):72-82.

Januškevičius V, Januškevičienė G, Zaborskienė G (2018) Quality of beef diaphragm meat in naturally occurring Sarcocystis infection in cattle. CJFS 50(8):331-335.

Januškevičius V, Januškevičienė G, Prakas P, Butkauskas D, Petkevičius S (2019) Prevalence and intensity of Sarcocystis spp. infection in animals slaughtered for food in Lithuania: original paper. Vet Med Praha 64(4).

Latif BMA, Al-Delemi JK, Mohammed BS, Al-Bayati SM, Al-Amiry AM (1999) Prevalence of Sarcocystis spp. in meat-producing animals in Iraq. Vet Parasitol 84(1-2):85-90.

Mavi SA, Teimouri A, Mohebali M, Yazdi MKS, Shojaee S, Rezaian M, Salimi M, Keshavarz H (2020) 
Sarcocystis infection in beef and industrial raw beef burgers from butcheries and retail stores: A molecular microscopic study. Heliyon 6(6):4171.

Meistro S, Peletto S, Pezzolato M, Varello K, Botta M, Richelmi G, Biglia C, Baioni E, Modesto P, Acutis P, Bozzetta E (2015) Sarcocystis spp. prevalence in bovine minced meat: a histological and molecular study. Ital J Food Saf 4(2).

Metwally AM, Abd Ellah MR, AL-Hosary AA, Omar MA (2014) Microscopical and serological studies on Sarcocystis infection with the first report of $S$. cruzi in buffaloes (Bubalus bubalis) in Assiut, Egypt. J Parasit Dis 38(4):378-382.

Mousa MM, Hiekal FA, El-Hoshy SM, Radwan MM, Abd El Naby WS (2016) Characterization of Sarcocystis species based on traditional and molecular methods in imported frozen buffalo meat in Egypt. Alex J Vet Sci 51(1):155-161.

Muhamed TA, Al-Barwary LTO (2016) Prevalence of Intestinal Parasites in the Intestine of Dogs (SheepKeeper, Owned, Pet and Stray) in Duhok Province, Kurdistan Region. JVST 7(6):379.

Saeid R, Nourollahi F, Masoud A, Fatemeh N (2009) Survey of Sarcocystis infection in slaughtered cattle in Kerman, Iran. Trop Anim Health Prod 41:16331635.

Shekarforoush SS, Razavi SM, Dehghan SA, Sarihi K (2005) Prevalence of Sarcocystis species in slaughtered goats in Shiraz, Iran. Vet Rec 156(13):418.

Taib M, Harhoura K, Aissi M, Chaouadi M, Djouhri Y (2016) Study of the bovine Sarcosporidiosis in the slaughterhouses of the North of Algeria: Case of the Slaughterhouses of El Harrach (Algiers). Cell Dev Biol 5(167):2.

Tian, M., Chen, Y., Wu, L., Rosenthal, B.M., Liu, X., He, Y., Dunams, D.B., Cui, L. and Yang, Z (2012) Phylogenetic analysis of Sarcocystis nesbitti (Coccidia: Sarcocystidae) suggests a snake as its probable definitive host. Veterinary parasitology, 183(3-4),:373-376.

Venu R, Hafeez MD (2000) Prevalence of sarcocystic infections in slaughtered domestic ruminants in Tirupati (AP). Indian Vet J 77(2): 165-166.

Wee SH, Shin SS (2001) Experimental induction of the two-host life cycle of Sarcocystis cruzi between dogs and Korean native calves. Korean J Parasitol 39(3):227.

Zangana IK, Hussein SN (2017) Prevalence of Sarcocystis species (Sarcocystis ovicanis and Sarcocystis capricanis) in tongue muscle of sheep and goats in Duhok province, Kurdistan region, north Iraq. AROThe Scientific Journal of Koya University 5(1):36-40. 